\title{
SIBS WITH CARDIAC GLYCOGENOSIS
}

\author{
BY \\ G. M. LEWIS and T. W. SUTHERLAND \\ From the Departments of Paediatrics and Child Health, and Pathology, The University of Leeds
}

(RECEIVED FOR PUBLICATION APRIL 6, 1964)

Cardiac glycogenosis is a disease causing death in early infancy due to the accumulation of glycogen in the heart and other organs. The inborn error of metabolism responsible for the deposition of glycogen in heart muscle has been found to be due to a deficiency of $x$-glucosidase (Hers, 1963). Previously, other workers had not identified an enzyme disturbance (Cori, 1954; Stoeckle, Goldman, and Webb, 1961). The glycogen deposited is of normal structure (DeWitt Stetten and Stetten, 1960).

The abnormal deposition of glycogen is not confined to the heart, but occurs also in skeletal muscle, smooth muscle, and the nervous system, and may result in enlargement of the tongue (Di Sant' Agnese, Andersen, Mason, and Bauman, 1950), muscle weakness (Childs, Crose, and Henderson, 1952), and constipation due to involvement of Auerbach's plexus (Muller, Bellet, and Ertrugrul, 1961).

The two infants described in this paper were brothers and the only children of healthy parents. The parents are not related to each other, though they both come from families in the same city, and there is no history of death in infancy among their relatives.

\section{Case 1}

Clinical Findings. A male infant, born at home on April 23,1959 , weighing $7 \mathrm{lb} .(3 \cdot 2 \mathrm{~kg}$.), was well until the age of 2 months when he was noticed to have a repetitive cough and to sweat profusely. The parents suspected that he had an occasional rise in temperature and described him as being very constipated. By the age of 3 months he was less well, he took feeds poorly, often vomited, and gained little weight. When 4 months old he was obviously ill and was referred to hospital.

On admission he was wasted and dehydrated. The temperature was $99 \cdot 6^{\circ}$ F. $\left(37 \cdot 6^{\circ} \mathrm{C}\right.$.); the pulse rate 120 a minute: the respiration rate $\mathbf{4 0}$ a minute; and he weighed $11 \mathrm{lb}$. $13 \frac{1}{2} \mathrm{oz} .(5 \cdot 37 \mathrm{~kg}$.). He waved his arms as if in pain, was dyspnoeic, constantly whimpering, and pale but not cyanosed. Apart from an expression of exhaustion, the facial appearance was normal and there was no macro- glossia. The lips were dry and there was an extensive monilial infection involving the tongue and buccal cavity. Anteriorly the chest was protruberant, and clinically the heart was very greatly enlarged. The heart sounds were soft and there were no murmurs. The blood pressure was $80 / 45 \mathrm{~mm} . \mathrm{Hg}$. The liver was palpable 1 in. $(2 \cdot 5$ $\mathrm{cm}$.) below the costal margin in the right mid-clavicular line. No enlargement of the spleen was detected.

Radiography showed gross enlargement of the heart. Screening of the chest showed greatly enlarged heart with little movement with each heart beat.

Electrocardiogram. P-R interval 0.08 sec., QRS 0.08 sec.; ST depression and inverted $T$ waves in all standard leads and V3R and V2-6; deep $Q$ waves in all standard leads and V5-6: right and left ventricular hypertrophy with strain.

Subsequent Course and Therapy. The oral thrush responded quickly and completely following the local application of $1^{\circ} \mathrm{o}$ aqueous gentian violet, and the dehydration present on admission was corrected by oral fluids. A provisional diagnosis of cardiomyopathy was made and the infant was treated with digoxin. No appreciable change in the general condition resulted, apart from a fall in pulse rate and a reduction of liver enlargement. A third heart sound developed at the apex and a soft systolic murmur became audible at the lower left sternal border.

Intermittent pyrexia was a feature of the four weeks during which the patient was in hospital. Temperatures of $101^{\circ} \mathrm{F} .\left(38 \cdot 3^{\circ} \mathrm{C}\right.$.) associated with marked sweating occurred on most days. Two weeks after admission he developed a temperature of $103^{=} \mathrm{F} .\left(39 \cdot 4^{\circ}\right.$ C. $)$ which persisted for three days and was accompanied by dullness on percussion, bronchial breathing and fine crepitations at the left base, and generalized rhonchi throughout the chest. During the four weeks he was in hospital the absolute and differential white cell counts were normal, and a blood culture at the time of high pyrexia was sterile. The patient was treated with tetracycline during this illness. Signs of collapse of lung at the left base persisted until his death three weeks later. Four days before death, signs suggestive of tricuspid incompetence developed; the neck veins became distended and showed 


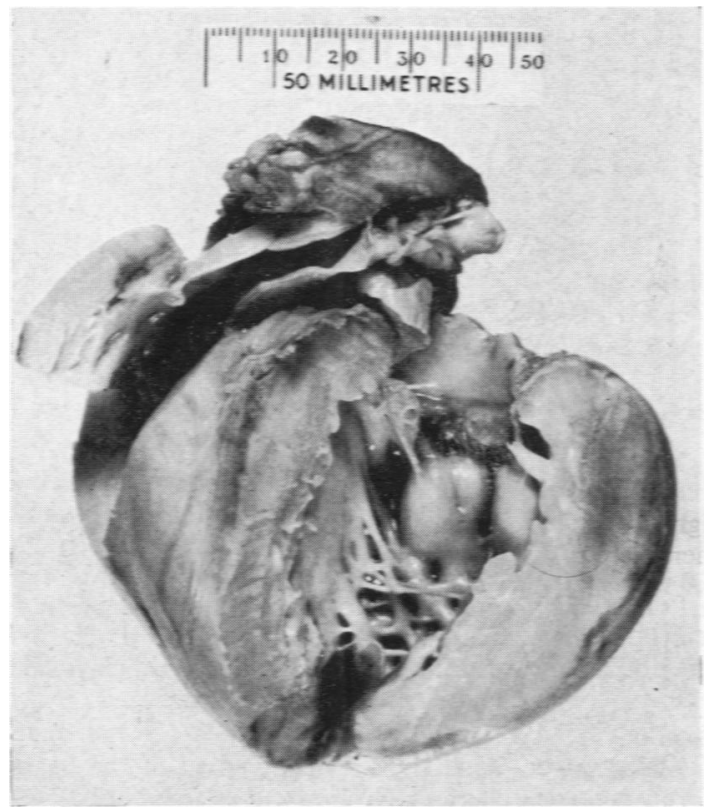

Fig. 1.-Case 1. The heart, opened to show the great thickening of the wall of the left ventricle.

systolic pulsation; and the systolic murmer at the lower border of the sternum was more marked. During the last four days he became ashen grey and physical signs of

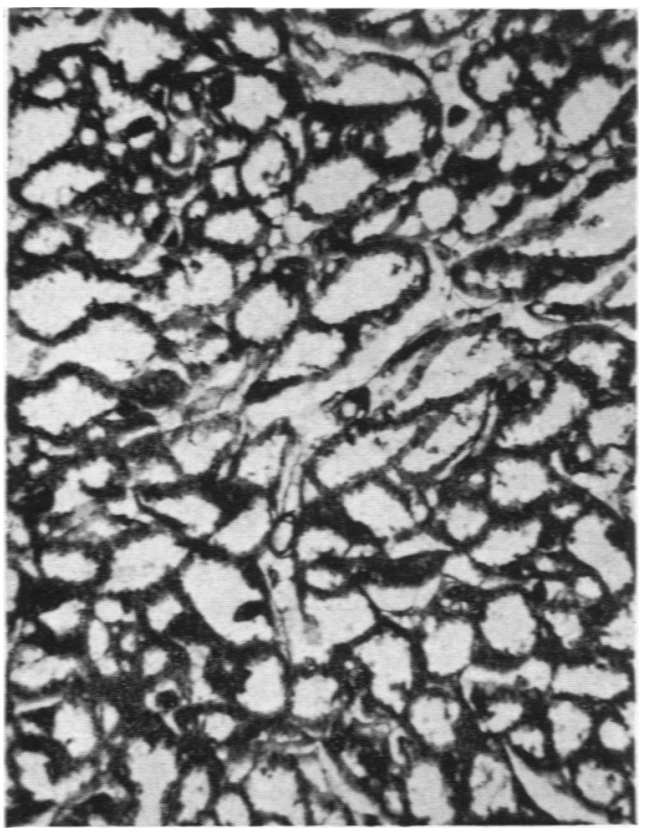

Fig. 2.-Case 1. The myocardium of the left ventricle, showing clear spaces in the fibres. (van Gieson and Verhoeff. $\times 490$.) bronchopneumonia developed. The temperature rose persistently, and the cause of the illness was not influenced by intramuscular chloramphenicol. The baby was $5 \frac{1}{2}$ months at the time of death.

Necropsy. The body was of a male infant of poor development and nutrition.

The heart (Fig. 1) was strikingly enlarged, weighing $220 \mathrm{~g}$.: the normal weight at this age is $29 \mathrm{~g}$. (Coppoletta and Wolbach, 1933). The increase in weight was largely the result of thickening of the walls of both ventricles,

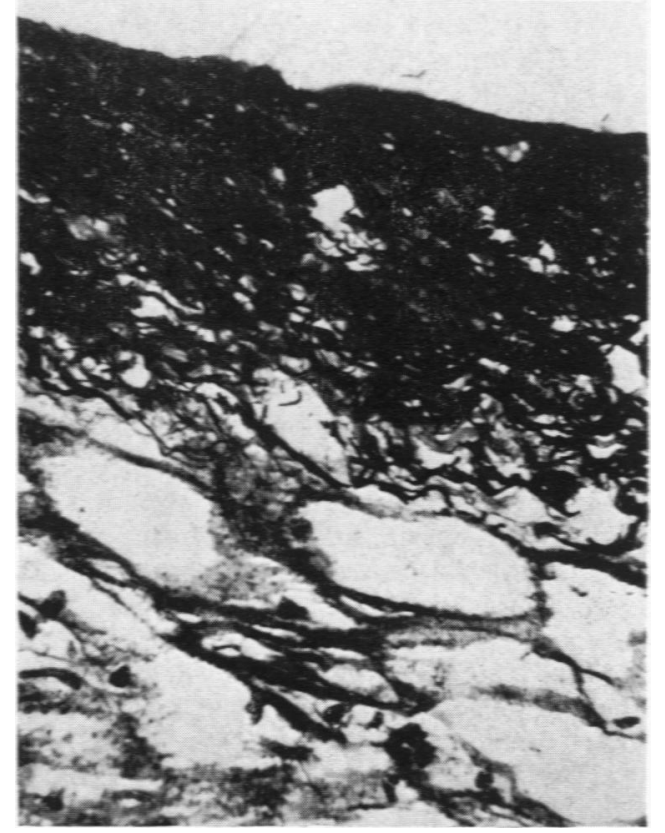

Fig. 3.--Case 1. The sub-endocardial stroma, slightly thickened, is rich in elastic fibres, appearing black. Underlying muscle fibres show clea- spaces. (van Gieson and Verhoeff. $\times 490$.

including the intraventricular septum. The anterior wall of the left ventricle measured up to $2 \mathrm{~cm}$. in thickness, that of the right, up to $1 \mathrm{~cm}$. The subendocardial stroma of the left ventricle was thickened, white, and opaque. The foramen ovale was patent. The cut surface of the myocardium was uniformly pale. The valves, coronary arteries, and great vessels were normal.

The liver was pale and weighed $280 \mathrm{~g}$. The normal weight of the liver at this age is $188 \mathrm{~g}$. (Coppoletta and Wolbach, 1933). The thymus gland was small and bore numerous petechiae. The lower lobes of the lungs showed purplish areas, suggesting collapse and slight oedema, but no sign of pneumonic consolidation. The brain and other organs appeared normal.

Histology. In the left ventricle almost all myocardial fibres were uniformly enlarged, and their cytoplasm was mostly replaced by a clear space (Fig. 2). Granular material in the peripheral parts of the fibres stained like glycogen. Fixation with formol saline made the amount 
and distribution of the glycogen difficult to assess, but the appearances were consistent with glycogen disease. The subendocardial stroma (Fig. 3) was rich in elastic fibres and slightly thickened.

Sections of lung showed bronchopneumonia, and glycogen was present in smooth muscle, in walls of small vessels, and in connective-tissue cells.

\section{Case 2}

Clinical Findings. A male infant was born at home on August 6, 1960, ten months after the death of his brother (Case 1). The birth weight was $8 \mathrm{lb}$. (3.62 kg.). Apart from a hare-lip, he appeared normal in all respects until the age of 6 weeks when he developed a persistent cough, profuse sweating, and refused feeds. Like his brother he failed to gain weight, became pale and ill, and developed severe oral moniliasis. He was not constipated despite the poor fluid intake and profuse sweating. When 3 months old he was admitted to hospital and died two weeks later.

On admission his weight was $10 \mathrm{lb} .2 \mathrm{oz}$ ( $4 \cdot 6 \mathrm{~kg}$.), the temperature $100^{\circ} \mathrm{F}$. $\left(37 \cdot 8^{\circ} \mathrm{C}.\right)$, the pulse rate 140 a minute, and the respiration rate 60 a minute. The infant lay exhausted and hypotonic. The buccal cavity and tongue were coated with thrush. Many small fieshy discrete lymph nodes were palpable in the axillae and groins. The anterior chest wall was protruberant and the jugular veins filled to one inch above the clavicle when he was reclined at forty-five degrees. Clinically the heart was greatly enlarged. The heart sounds were abnormally soft in character. No murmurs were heard.

The liver and spleen were palpable, the margin of the liver being three finger breadths below the costal margin in the right mid-clavicular line. The deep reflexes were present.

\section{Radiography showed gross cardiac enlargement.}

Electrocardiogram. The P-R interval was 0.09 sec.; QRS 0.06 sec.; ST depression in all standard leads and in VI; $T$ was inverted in lead III, V3R-V2. Biventricular hypertrophy was obvious; and there was supraventricular tachycardia, in places suggesting flutter with $2: 1$ block. Deep $Q$ waves in I, II, V4-6.

Subsequent Course and Therapy. The oral thrush cleared quickly with $1 \%$ aqueous gentian violet applied locally. Pyrexia $102^{\circ} \mathrm{F}$. (38.9 $9^{\circ} \mathrm{C}$.), increased dyspnoea, and movement of the alae nasae developed, and signs of left lower lobe collapse together with generalized fine expiratory rhonchi suggested commencing bronchopneumonia. There were, however, no changes in the total or differential white cell count and no appreciable response to achromycin. Terminally the temperature showed a progressive rise. Digitalization produced no improvement. At the time of death the baby was $3 \frac{1}{2}$ months old.

Necropsy. The body was that of a male infant of poor development and nutrition with pronounced abdominal distension.
The heart was globular and strikingly enlarged, weighing $212 \mathrm{~g}$. in contrast to the normal weight at this age of 27 g. (Coppoletta and Wolbach, 1933). The increase in weight was largely the result of a thickening of the walls of both ventricles. The wall of the right ventricle measured up to $0.6 \mathrm{~cm}$. in thickness and that of the left up to $2 \mathrm{~cm}$. The right atrium appeared normal in shape; its cavity measured approximately $4 \times 1.5 \mathrm{~cm}$. The left atrium also appeared normal; its cavity measured $4 \times 1.6 \mathrm{~cm}$. The cut surface of the myocardium was uniformly pale. The endocardium and valves appeared normal. No septal defect or other congenital malformation could be detected. The ductus arteriosus was occluded.

The thymus gland bore a few petechiae and weighed $5 \mathrm{~g}$. The left lung, extensively collapsed, weighed $41 \mathrm{~g}$; the right, expanded and bulky, weighed $51 \mathrm{~g}$. On section there was no sign of pneumonia. The liver was pale and weighed $240 \mathrm{~g}$.: the normal weight of the liver at this age is $160 \mathrm{~g}$. (Coppoletta and Wolbach, 1933). The spleen appeared normal and weighed $11 \mathrm{~g}$. The kidneys appeared normal and weighed $42 \mathrm{~g}$. together. The intestines were greatly distended with gas, accounting for the abdominal distension. The brain and other organs appeared normal.

\section{Histology.}

Heart. Myocardial fibres in sections stained with haematoxylin and eosin, after formol fixation, were uniformly enlarged. Most of the cytoplasm was replaced by a vacuole or clear space and only a narrow eosinophilic rim remained. The nuclei were small, uniform, and usually central. The subendocardial connectivetissue appeared normal.

Sections stained with Best's carmine after alcoholic fixation showed that all fibres were rich in crimson-stained material (Fig. 4). A section stained with Best's carmine after diastase showed fibres devoid of such material (Fig. 5). These appearances indicated excessive accumulation of glycogen. Staining with the periodic acidSchiff method gave similar results. Sections from blocks fixed in formol saline showed much less glycogen.

LIVER. Sections showed hepatic epithelium uniformly laden with glycogen, mostly in the form of fine granules. Sections from blocks fixed in formol saline showed almost as much glycogen as sections from blocks fixed in alcohol.

OTHER Organs. Voluntary muscle in some parts of the tongue showed swelling and vacuolization of fibres, in sections with haematoxylin and eosin. Some of the vacuoles contained coarse granules of glycogen stained crimson with Best's carmine. Similar but less prominent vacuoles involved the oesophageal voluntary muscle. Other structures rich in glycogen included the epithelium of the distal convoluted tubules of the kidney, cells of the adrenal cortex, ganglion cells in the plexuses of Auerbach and Meissner, nerve cells and astrocytes in the basal ganglia (Fig. 6), smooth muscle in the walls of blood vessels, and connective-tissue cells, for example, chondro- 


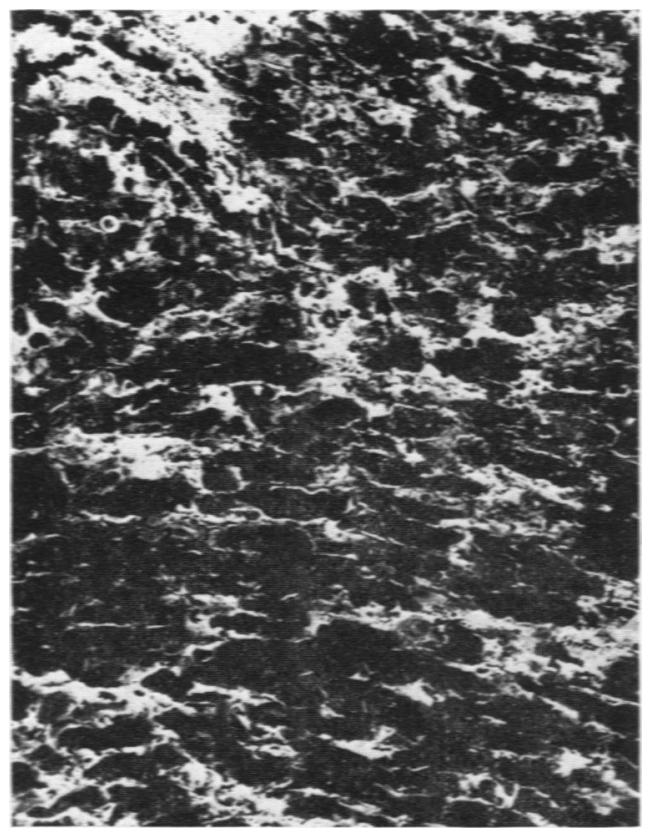

Fig. 4.-Case 2. The myocardium of the left ventricle. Accumulations of glycogen appear black. (Best's carmine. 138.)

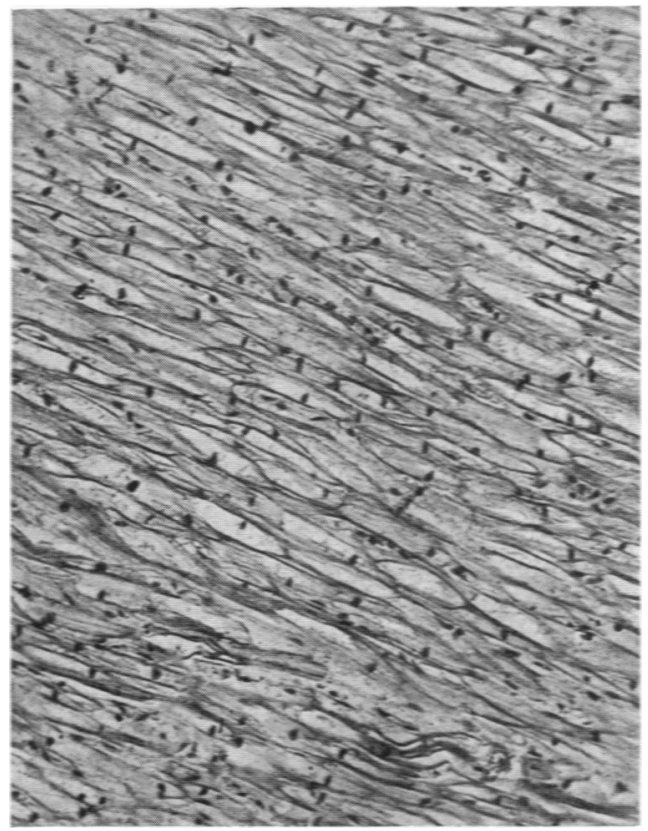

FKG. 5.-Case 2. The myocardium of the left ventricle. Myocardial fibres are swollen and empty-looking. (Best's carmine preceded by diastase. $\times 138$.

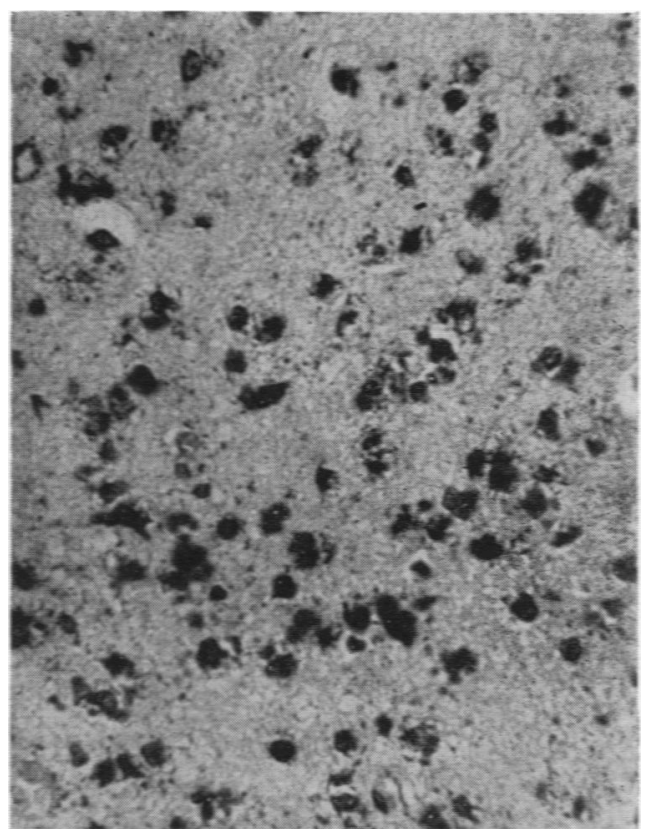

FiG. 6. - Case 2. Neurones and glial cells in the basal ganglia laden with glycogen. The glycogen appears black. (Best's carmine. $\times$ 490.)

cytes. A little intracellular glycogen could also be detected in the splenic pulp and the thymus gland.

The lungs showed patchy collapse and accumulation of macrophages in occasional alveoli.

\section{Discussion}

The clinical onset and presentation were similar in both infants; failure to thrive, repetitive cough, profuse sweating, and whimpering misery being the most striking symptoms. The dominant physical findings were gross cardiomegaly and soft heart sounds.

Though both infants were hypotonic and weak, their muscular weakness was not severe and not of help in reaching the diagnosis of cardiac glycogenosis. Neither infant showed any enlargement of the tongue. Both infants perspired profusely even when apyrexial, a feature described as occurring during feeds by Ehlers, Hagstrom, Lukas, Redo, and Engle (1962). Terminally, both patients developed signs of left lower lobe collapse associated with high temperature but with no increase in the white cell count. A poor leucocyte response does not appear to be a feature of the disease, as other workers have recorded infection with high white cell counts (Clement and Godman, 1950; Langewisch and Bigler, 1952). 
The electrocardiograms in the two cases were typical of glycogen storage disease, the ECG changes being similar to those reported by Caddell and Whittemore (1962) and Ehlers et al. (1962). The short P-R interval was possibly due to increased glycogen in the myocardium (Caddell and Whittemore, 1962). Ehlers et al. (1962) and Caddell and Whittemore (1962) suggested that the finding of a short P-R interval was of value in distinguishing patients with cardiac glycogenosis from infants with left ventricular hypertrophy due to such other causes as endocardial fibroelastosis or myocarditis.

At necropsy on Case 1 the subendocardial stroma was thickened, white, and opaque, closely resembling subendocardial fibroelastosis, which was the provisional diagnosis pending microscopical findings. Wilson and Clark (1960) described three sibs, two of whom had endocardial fibroelastosis associated with cardiac glycogenosis, the endocardial thickening being greater in the longer surviving infant. In the infants described in this paper there was obvious thickening of the subendocardial stroma in Case 1 (who lived $5 \frac{1}{2}$ months), but there was no endocardial change on microscopy in Case 2 (who lived $3 \frac{1}{2}$ months). These findings, therefore, support the suggestion that the formation of endocardial fibroelastosis in cases of cardiac glycogenosis may be related to the length of survival.

\section{Summary}

The clinical and pathological findings in two sibs who suffered from cardiac glycogenosis (Pompe's disease) are described. The first infant (Case 1) was diagnosed only after microscopy of post-mortem specimens. The diagnostic clinical features of this disease are discussed in relation to other cases reported in the literature. The formation of endocardial fibroelastosis is discussed in relation to the length of survival.

We wish to record our thanks to Professor W. S. Craig for his encouragement and permission to publish these cases.

\section{REFERENCES}

Caddell J. L and Whittemore, R. (1962). Observations on generalized glycogenosis with emphasis on electrocardiographic changes. Pediatrics, 29. 743

Childs. A. W.. Crose. R. F.. and Henderson. P. H. (1952). Glycogen disease of the heart-report of two cases occurring in siblings. ibid., 10. 208.

Clement. D. H.. and Godman. G. C. (1950). Glycogen disease resembling mongolism. cretinism. and amytonia congenita: case report and review of literature. J. Pediat.. 36. 11.

Coppoletta. J. M., and Wolbach. S. B. (1933). Body length and organ weights of infants and children. A study of the body length and normal wieghts of the more important vital organs of the body between birth and twelve years of age. Amer. J. Path.. 9. 55.

Cori. G. T. (1954). Glycogen structure and enzyme deficiencies in glycogen storage disease. Harvey Lect., (1952-53). 48, 145.

DeWitt Stetten. Jr., and Stetten. M. R. (1960). Glycogen metabolism. Physiol. Rev.. 40. 505.

Di Sant' Agnese. P. A.. Andersen. D. H.. Mason. H. H. and Bauman, W.A. (1950). Glycogen storage disease of the heart. I. Report of two cases in siblings with chemical and pathologic studies. Pediatrics. 6. 402

Ehlers. K. H.. Hagstrom. J. W. C.. Lukas. D. S.. Redo. S. F., and Engle. M. A. (1962). Glycogen-storage disease of the myocardium with obstruction to left ventricular outflow. Circulation. 25, 96.

Hers. H. G. (1963). x-Glucosidase deficiency in generalized glycogenstorage disease (Pompe's disease). Biochem. J.. 86. 11.

Langewisch. W. H., and Bigler. J. A. (1952). Disorders of glycogen metabolism. Pediatrics, 9, 263.

Muller. O. F.. Bellet. S.. and Ertrugrul. A. (1961). Glycogen-storage disease. Report of a case with generalized glycogenosis and review of the literature. Circulation, 23, 261.

Stoeckle. H., Goldman, A. S.. and Webb. J. A. (1961). Generalized glycogenosis. Amer. J. Cardiol.. 8, 675.

Wilson, R. A., and Clark, N. (1960). Endocardial fibroelastosis associated with generalized glycogenosis. Pediatrics, 26. 86. 